\title{
An Examination of African American NCAA DI-FBS Football Coaches: A Five-Year Update
}

\author{
Trevor Bopp and Michael Sagas \\ University of Florida
}

\begin{abstract}
Past studies have concluded that institutional and access discrimination remain potential deterrents in achieving a more diverse and equal representation of racial minority head coaches in college football. This study sought to examine and compare the career paths of all DI-FBS coaches to determine the potential continued existence of discrimination and its impact. Findings revealed an overall positive shift in the representation of African American coaches, particularly at the assistant coach level. Thus, the coaching career paths of current head coaches and coordinators appear to be paving a more equitable path for assistant and future coaches. However, the data also portray the existence of both institutional and access discrimination. Such biases facilitate and maintain an underrepresentation of African American coaches; and while the increased acceptance of upper-level coaches with diverse racial, playing, and coaching backgrounds suggests a positive shift toward racial equality among coaches, the movement for a balanced representation perseveres.
\end{abstract}

Keywords: African American, discrimination, football coach, NCAA

Based on a previous research suggestion that the candidate pool for a coaching position should be heavily occupied by former athletes of that sport (Everhart \& Chelladurai, 1998), it is reasonable to expect the racial composition of football coaching staffs to emulate the racial composition of football student-athletes. Such is not the case at the elite level of college football. In 2009-10 at the Division I level of college football, $45.8 \%$ of all student-athletes were African American (Zgonc, 2010b) compared with only $5.1 \%$ and $24.1 \%$ (12.6\% and $28.8 \%$ when historically black institutions [HBCUs] were included) of African American head and assistant coaches in 2008-09, respectively (Zgonc, 2010a). Such racial and ethnic inequalities between the players and coaches of a sport can lead to biased expectations and assumptions regarding participants. This can be witnessed in college football where it has been found that African Americans are 7.6 times more likely to be seen as a player than as a head coach (Cunningham, 2010); despite an historic 13 African

The authors are with the Department of Tourism, Recreation, and Sport Management, University of Florida, Gainesville, FL. 
Americans having been at the helm of programs participating at the most elite level of college football, Division I-FBS (Football Bowl Subdivision).

The scarcity of African American head coaches and the dissonance between the racial composition of student-athletes and coaching staffs provides validation for inquiries into potential and various forms of discrimination. Positional segregation, or stacking as it is more commonly referred to in the sports realm, has been researched as one potential cause for the lack of minority leadership in sports at the intercollegiate level (Sack, Singh, \& Thiel, 2005); as have homologous reproduction (Cunningham \& Sagas, 2005), access discrimination (Cunningham \& Sagas, 2005), and treatment discrimination (Sagas \& Cunningham, 2004). Such exclusionary, and often times implicit or subconscious, practices have vaulted concern regarding the underrepresentation of African American coaches to the forefront of social issues in college football. Yet another form of discrimination, institutional discrimination, can be used to examine the possible existence of certain means by which control and influence over institutional factors and access to resources in the college football coaching industry is maintained by the dominant group (McCrudden, 1982).

In 1993, Anderson addressed the potential reality of institutional discrimination in college football and its potential negative outcomes on coaches. Using data from the 2005 season, Finch, McDowell, and Sagas (2010) replicated his study to determine if a more equitable racial representation had taken place among college football coaching staffs. Both studies concluded that institutional and access discrimination, partly attributable to coaching career paths, remains a potential deterrent in achieving a more diverse and equal representation of African American head coaches. With the recent noteworthy increase in representation of African American college football coaches in 2010, this study sought to examine and compare the career paths of all DI-FBS coaches and compare them to those of the coaches analyzed in the Anderson (1993) and Finch et al. (2010) studies.

\section{Review of Pertinent Literature}

In any industry or field of work, there exists a path by which most employees travel to establish a career or reach the upper echelons of employment. Dependent upon the business conducted within the industry or field of work, that path may be paved through experience, education, apprenticeship, etc. For coaches in the field of sport, this path often takes one from player to graduate assistant to assistant coach and ultimately, to a head coaching position. However, the hierarchy of the positions within the coaching staff is usually dependent upon the sport, with football coaches seeming to have a longer (i.e., more coaching positions) path to navigate (Anderson, 1993). The career path of a college football coach typically begins with his playing days, after which he takes on the role of a graduate assistant or lower level assistant coach at, in all likelihood, the position he played. He next progresses through the hierarchical coaching ladder to an upper-level assistant coach or coordinator role. Eventually, his career path might reach the pinnacle of the coaching ladder as the head coach. It is from this progression we can deduce why student-athletes (former players of the game) most likely comprise the best applicants within a coaching candidate pool; and in turn, why the coaching field should be representative of the sport's student-athlete racial composition (Everhart \& Chelladurai, 1998). 
Anderson (1993) speculated that this coaching career path may unintentionally work against African Americans, as he found that the majority $(66.6 \%)$ of head coaches in 1990 had played either quarterback or along the offensive line. Similarly in $1990,68.9 \%$ of offensive coordinators were listed as having played in either of the two positions. This is a critical finding given that these highly centralized positions have historically and primarily been occupied by White athletes. Finch et al. (2010) found that in 2005, the percentage of head coaches having played quarterback or along the offensive line decreased to $45.4 \%$; even more telling, one third of all head coaches had played quarterback. Such findings provide evidence that the practice of stacking, which is the assigning of athletes to certain playing positions based on assumptions regarding one's athletic ability and race (Sack et al., 2005), continues to remain a potential influence, and adversely so for African Americans, on the career coaching outcomes of current and future players. Such stereotypical assumptions can result in the segregating of African American players into more peripheral, and subsequently less decisive and authoritative, positions on the playing field. Consequently, few African Americans are given the opportunity to be hired as coaches as a high percentage of college coaches are recruited from central, decision-making positions (Kamphoff \& Gill, 2008). Furthermore, "this lack of exposure to strategic decision making might be a disadvantage for Black players who aspire to become coaches and managers" (Sack et al., 2005, p. 315).

Researchers have employed a bevy of explanations, other than stacking and positional segregation, in discussions of potential discrimination toward African American coaches in intercollegiate athletics. Cunningham and Sagas (2005) examined the practice of homologous reproduction to explain negative impacts on the access of African Americans into the coaching field, finding same-race hiring practices to be prevalent in intercollegiate athletics. This remains a cause for concern given that $87.9 \%$ (952) of NCAA director of athletics, a common decisive figure in the head coach hiring process, in the 2008-09 academic year were White (Zgonc, 2010a). Similarly, $92.5 \%$ of DI-FBS university presidents, yet another key figure in the head coach hiring process, in 2010 were White (Lapchick, Hoff, \& Kaiser, 2011). This would suggest that the hiring of racially similar head football coaches facilitates the "good old boys" network, and in turn, maintains the authority of White males in collegiate leadership and management positions (Heilman, 2001; Lovett \& Lowry, 1994). Such institutionalized practices (i.e., policies, practices, and procedures that have over time become commonplace in a particular field or industry) oftentimes act as a means by which control and influence over institutional factors (e.g., salaries, employment, resources, opportunities, information, and human and social capital) is maintained (McCrudden, 1982). As such, it has been argued that college football coaching is a caste system that sends the message African Americans "are good enough to play but not to coach" (Agyemang \& DeLorme, 2010, p. 38).

A further implication is the continued lack of role models with whom African American athletes and coaches can emulate and identify, potentially limiting the intentions of said players and assistants to become a head coach (Hawkins, 2002; Kamphoff \& Gill, 2008; Sagas, Cunningham, \& Pastore, 2006). As such, fewer African Americans might assume the role of head coach, perpetuating the false expectation that a college football head coach need be White. Role incongruity demonstrates how these potential expectations can adversely impact African Americans' 
opportunities at gaining a head coaching position. Role congruity theory (Eagly \& Karau, 2002) can be a source to convey potential prejudices that might exist due to latent stereotyped characteristics of African American coaches that are incongruent with what individuals perceive to be the attributes necessary to hold a head coaching position; in this case, White. Consequently, African American coaches have been found to be viewed as less qualified than their White counterparts for head coaching positions (Sartore \& Cunningham, 2006) and that the attributes of African American coaches do not match with the attributes need to be a head coach. This perceived "lack of fit" (Burgess \& Borgida, 1999) further perpetuates discrimination and unequal coaching opportunities for African Americans. Research has found that discrepancies in media portrayals of African American athletes and coaches have furthered stigmas and stereotypes that detrimentally impact their coaching chances (Buffington, 2005; Cunningham \& Bopp, 2010; Dufur \& Feinberg, 2009; Woodward, 2004).

The resultant impact of these theories in practice is a lack of human and social capital for African American coaches when compared with their White counterparts. More specifically, as African Americans are relegated to the peripheral positions of wide receivers, running backs, and defensive backs, the skills and knowledge they learn and develop are designed to enhance play at those particular positions; coaching positions that historically have not led to head coaching roles (Anderson, 1993; Finch et al., 2010). Similarly, the social networks and capital of coaches and players holding these positions might struggle to extend beyond the boundaries of said positions. Such disparities in human and social capital among coaches in college football have been found to lead to lower levels of career success, career satisfaction, and career advancement (Sagas \& Cunningham, 2005). Thus, the social networks and human capital of African Americans, impacted negatively by institutional discrimination, have been argued to hinder the "career advancement, upward mobility, and career aspirations among American ethnic minorities" (Anderson, 1993, p.66).

However, with recent support from the National Collegiate Athletic Association (NCAA) and urges from organizations such as the Black Coaches and Administrators (BCA), the representation of African American college football coaches is steadily, albeit slowly, increasing. The purpose of this study is to identify any potential gains made by African American coaches in DI-FBS football. A secondary aim of this study is to determine in what ways, if any, African American coaches are impacted by the coaching career paths of current head coaches and coordinators. Providing an update to, and expansion of Finch et al.'s (2010) and Anderson's (1993) studies should help to identify changes in the coaching representation of African Americans. The following research questions were designed with this aim; as well as to expand the work on institutional discrimination by assessing potential homologous reproduction and access discrimination.

\section{Research Question 1:}

What is the proportion of African American and White head and assistant coaches in DI-FBS in 2010, and do these proportions differ from those published by Finch et al. (2010) and Anderson (1993)? 


\section{Research Question 2:}

Will White head coaches have more White assistant coaches on their staff than African American head coaches, and conversely, will African American head coaches have more African American assistant coaches on their staff than White head coaches?

\section{Methodology}

\section{Data Collection and Analysis}

Data on football coaches were collected before, during and immediately following the 2010 spring practices of all 120 DI-FBS programs. However, at the time of data collection one program had not posted their coaches' biographical information, reducing the number of programs by one $(N=119)$. Detailed biographical information can frequently be found on the profile pages of a football teams' official athletic department website. Data were collected regarding race, current position coached, and position played in college for all head and assistant coaches, as well as offensive and defensive coordinators. Additional data were collected regarding the position coached for all head coaches and offensive and defensive coordinators before obtaining a position at or above the coordinator level. Part-time coaches, strength and conditioning coaches, graduate assistants, directors of football operations, and other football staff members were not included in the data collection.

Data regarding current coaching positions and the positions played in college were grouped and coded similarly to Finch et al.'s (2010) study. Coaches were grouped and coded into the following categories: (1) quarterback; (2) offensive lineman; (3) running back or wide receiver (including tight end); (4) defensive lineman or linebacker; (5) cornerback or safety; and (6) did not play collegiate football (for the positions played analysis). In addition, kickers, punters, and special team unit members were grouped as (7) special teams. As it was organized in Finch et al.'s (2010) study, the data coding was slightly different from Anderson's (1993) study with the combination of defensive lineman and linebacker into the same category. It is also possible for coaches to be involved with the instruction of multiple positions. When coaches were listed as having multiple responsibilities, the position first listed in the coach's bio was coded and used. For example, a coach listed on the web site as serving the role of both quarterbacks and running backs coach was coded into the quarterback category. This was to ensure coaches would only be counted once in the study.

The race of the coaches analyzed was determined by use of his head shot on the athletic department web site. Coaches were coded as White, African American, or Other. A potential limitation of this method is the subjectivity that is involved with coding race via surface-level characteristics, as well as the potential failure to account for multiracial and self-identified individuals. It is important to note this challenge as it is yet another threat that adds to the difficulty in "obtaining 'valid' data concerning race and ethnicity" (Armstrong, 2011, p. 97). Nevertheless, it could be argued that this methodology is appropriate due to society's tendency to judge, make decisions, and formulate assumptions based on one's physical 
appearance. Furthermore, similar methodologies have been successfully used in the sport literature studying race and coaching (e.g., Cunningham \& Bopp, 2010; Finch et al., 2010) and it has even been argued that the methodology is appropriate, as the perceptions of others have been found to be more impactful on labor market inequalities (Telles \& Lim, 1998). To help strengthen rater reliability of a coach's race, three football programs were randomly selected and codified by two independent raters, separate from the lead author. The coding of the coaches was matched $100 \%$ by each of the three raters, suggesting reliability of the investigator's racial coding. If data (i.e., race, current position coached, position played, and prior coaching position) could not be found on a certain coach, he was removed from the particular analysis of the study. Furthermore, if the race of a coach could not be determined or if he was not coded as being either White or African American, he was removed from the sample $(N=1,148)$.

A series of Chi-square analyses were used to determine potential differences over time in the racial demographics and playing and coaching positions of all current coaches. To answer Research Question 1, a Chi-square analysis determined potential differences in the current proportion of African American and White head coaches, offensive and defensive coordinators, and assistant coaches compared with those published by Finch et al. (2010) and Anderson (1993). Furthermore, Chi-square analyses were run on playing and coaching experience of all assistant coaches and head coaches to determine any possible differences from past time frames. A Chi-square analysis was also run on the racial make-up of African American and White head coaches' coaching staffs to determine if any significant differences existed.

\section{Results}

All but one football program had their 2010 coaching staffs posted online at the time of data collection, resulting in an analysis of 119 of the 120 DI-FBS teams. The resultant tally of coaches was 1,148 ; of which, $71.3 \%(n=818)$ were White and $28.7 \%(n=330)$ were African American. Coaches coded as "other" were dropped from the analysis. This was not significantly different than the coaching demographics of 2005 , where $74.6 \%(n=812)$ of the coaches were White and $25.4 \%(n=276)$ were African American. However, the decrease in the gap between African American and White coaches altered the representation of racially diverse coaches to a more expected level (Everhart \& Chelladurai, 1998). Providing a closer examination into the racial proportion of Whites and African Americans in particular coaching positions, significant differences were found for changes in coaching representation among head coaches, defensive coordinators, and assistant coaches (Table 1).

With the record number of African American head coaches at the helm of DI-FBS programs, it was no surprise to find significant differences in the coaching representation of African American and White head coaches from 1990 to $2005-2010, \chi^{2}(2, n=319)=9.05, p=.01$. A significant linear-by-linear association between the three years was also found, $\chi^{2}(1, n=319)=6.03, p=.01$, as African Americans represented 11.2\% $(n=13)$ of all head coaches in 2010; up from $2.6 \%(n=3)$ in 2005. Likewise, a significant difference, $\chi^{2}(2, n=326)=$ $7.21, p<.05$ and linear-by-linear association $\chi^{2}(1, n=326)=6.08, p=.01$, were found for defensive coordinators as African American representation increased to 


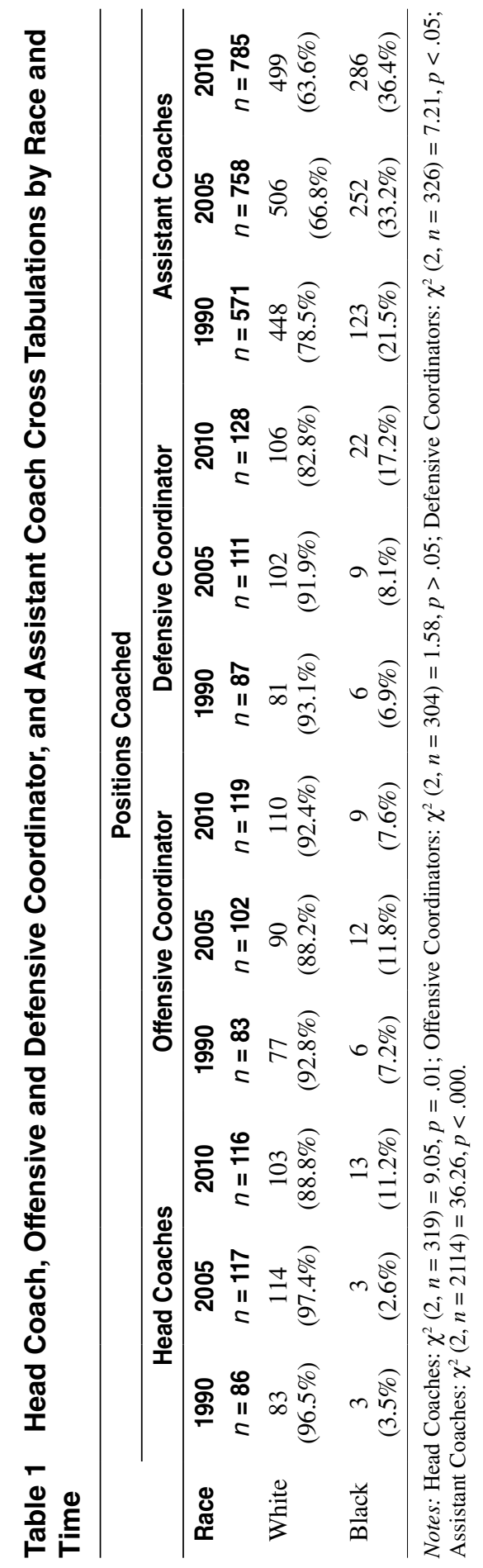


$17.2 \%(n=22)$ from $8.1 \%(n=9)$ in 2005 and 6.9\% $(n=6)$ in 1990. Similarly, a significant difference, $\chi^{2}(2, n=2114)=36.26, p<.000$ and linear-by-linear association $\chi^{2}(1, n=2114)=32.18, p<.000$, were found among assistant coaches as African American representation increased to $36.4 \%(n=286)$ from $33.2 \%(n=$ $252)$ in 2005 and $21.5 \%(n=123)$ in 1990 . Thus, significant positive trends were witnessed among African American coaching representation at the critical positions of head coach and defensive coordinator, as well as among overall assistant coaching positions (see Table 1).

\section{Assistant Coaches Position Coached by Race and Time}

Four distinct cross tabulations were used to further analyze potential significant changes among the assistant coaches in the sample. The first two cross tabulations examined potential representation differences in the race of assistant coaches by his coaching position from 2005 to 2010 . Complete results from the data analysis of representation differences in the race of assistant coaches by their coaching position from 2005 to 2010 can be found in Table 2. A significant difference was found for White assistant coaches $\chi^{2}(5, n=1005)=46.26, p<.000$ but not for African Americans $\chi^{2}(5, n=538)=10.13, p>.05$. The percentage of White assistant coaches decreased or remained the same in each coaching position except for running back and wide receiver coach, where the percentage increased from $29.2 \%(n=148)$ in 2005-30.9\% $(n=154)$ in 2010. Decreases, and/or equalities, in the percentage of White assistant coaches were found in the remaining coaching positions: quarterbacks, $10.1 \%(n=51)$ in $2005-7.0 \%(n=35)$ in 2010; offensive line, $21.2 \%(n=107)$ in $2005-21.2 \%(n=106)$ in 2010; and defensive line and linebackers, $25.5 \%(n=129)$ in $2005-22.8 \%(n=114)$ in 2010 . The greatest decrease among White assistant coaches was witnessed in their departure from coaching the defensive backs and safeties position where there was a decline from $14.0 \%(n=71)$ in $2005-10.2 \%(n=51)$ in 2010 .

Conversely, the defensive backs and safeties coach is the one position for which African American assistant coaching percentages increased, 18.7\% $(n=47)$ in $2005-24.8 \%(n=71)$ in 2010. Similar to the White assistant coaches, percentages were in decline for African Americans coaching the quarterback, $0.8 \%(n=2)$ in $2005-0.7 \%(n=2)$ in 2010; offensive line, $2.4 \%(n=6)$ in $2005-1.7 \%(n=5)$ in 2010; and running back and wide receiver, $45.8 \%(n=115)$ in $2005-42.7 \%(n=$ 122 ) in 2010. The greatest decrease among African American assistant coaches was witnessed in their departure from coaching the defensive line and linebacker positions where a decline was witnessed from $32.5 \%(n=82)$ in $2005-27.6 \%(n=$ $79)$ in 2010 . The addition of the special teams coach category potentially skewed the data between the 2005 and 2010 seasons.

\section{Assistant Coaches Position Played by Race and Time}

The next set of cross tabulations examined potential representation differences in the race of the assistant coach by his playing position from 2005 to 2010. Again, the addition of the special teams coach category potentially skewed comparisons of the data between the 2005 and 2010 seasons. Similar to prior analyses, when the playing position of an assistant coach could not be found, he was coded under Did Not Play. Complete results from the data analysis can be found in Table 3. No 


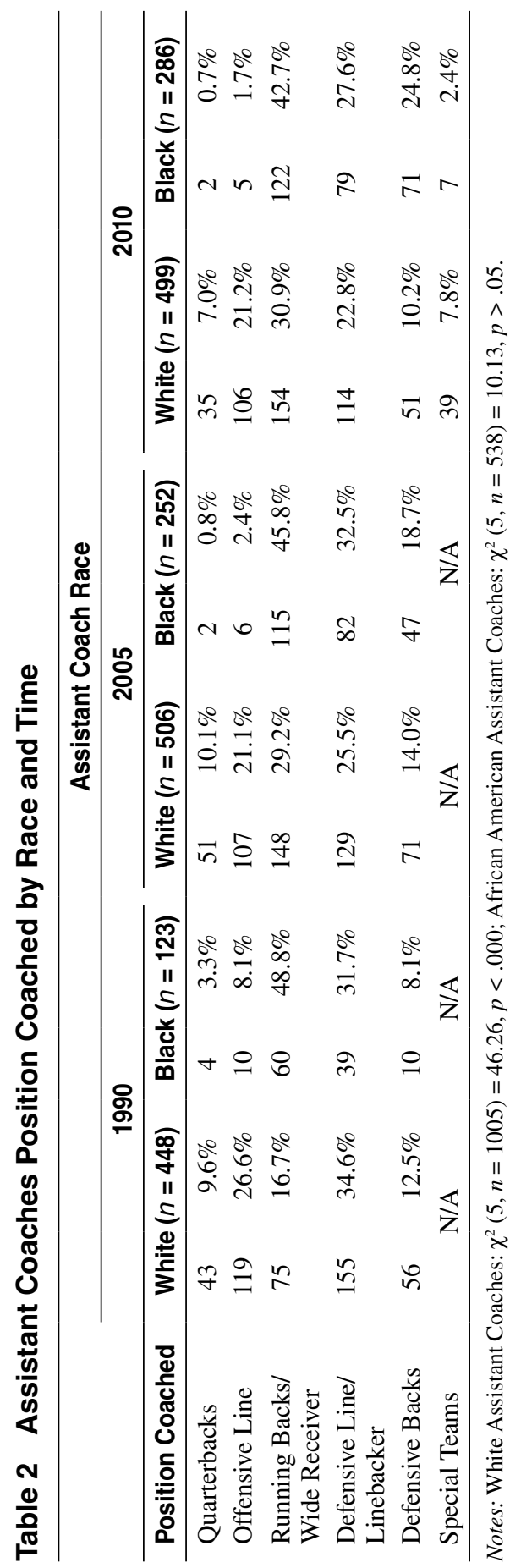




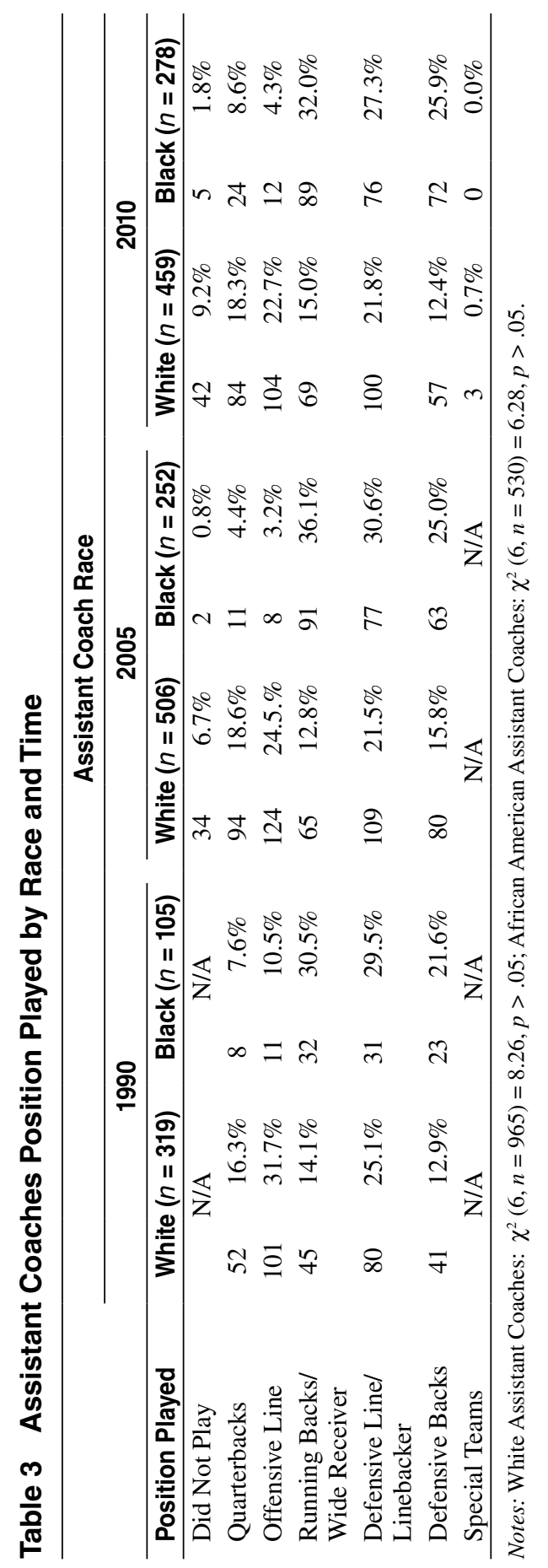


significant differences were found in the positions played from 2005 to 2010 for White, $\chi^{2}(6, n=965)=8.26, p>.05$, and African American assistant coaches, $\chi^{2}$ $(6, n=530)=6.28, p>.05$. However, percentage increases in coaches' playing positions for Whites were found for running back and wide receiver, $12.8 \%(n=$ $65)$ in $2005-15.0 \%(n=69)$ in 2010 , and defensive line and linebacker, $21.5 \%$ $(n=109)$ in $2005-21.8 \%(n=100)$ in 2010. Conversely, percentage decreases in playing positions among White assistant coaches were found at the quarterback, $18.6 \%(n=94)$ in $2005-18.3 \%(n=84)$ in 2010 ; offensive line $24.5 \%(n=124)$ in $2005-22.7 \%(n=104)$ in 2010 ; and the defensive back and safety positions, $15.8 \%(n=80)$ in $2005-12.4 \%(n=57)$ in 2010 .

Percentage increases in playing positions of African American coaches were found for quarterback, $4.4 \%(n=11)$ in 2005-8.6\% $(n=24)$ in 2010; offensive line $3.2 \%(n=8)$ in $2005-4.3 \%(n=12)$ in 2010; and defensive back and safeties, $25.0 \%(n=63)$ in $2005-25.9 \%(n=72)$ in 2010 . The largest increase among the playing positions of African American assistant coaches was at quarterback, where the coaches having played that position more than doubled from 11 to 24 . Percentage decreases in playing positions for African American coaches were found for running back and wide receiver, $36.1 \%(n=91)$ in $2005-32.0 \%(n=89)$ in 2010; and defensive line and linebackers, 30.6\% $(n=77)$ in $2005-27.3 \%(n=76)$ in 2010.

\section{Frequency of Head Coaches by Prior Coaching and Player Positions}

The position of head coach was also further analyzed by running cross tabulations on their playing positions, as well as the coaching positions they held before becoming a coordinator or head coach. As Finch et al. (2010) discovered, it was common for head coaches to have been an offensive or defensive coordinator before becoming a head coach. Therefore, the coaching experience of head coaches before obtaining one of those three positions (i.e., head coach, offensive coordinator, or defensive coordinator) was examined. There were no significant differences found between 2005 and 2010 in the coaching positions head coaches held before becoming a coordinator or head coach, $\chi^{2}(4, n=205)=3.19, p>.05$. Complete results can be seen in Table 4. Similarly, there were no significant differences between the playing positions of head coaches in 2005 and $2010, \chi^{2}(5, n=214)=2.29, p>$ .05 . However, complete results can be seen in Table 5 .

\section{Table 4 Frequencies of Head Coaches by Prior Coaching Position by Time}

\begin{tabular}{lcccc}
\hline Prior Position Coached & \multicolumn{2}{c}{$\mathbf{2 0 0 5}(\boldsymbol{n}=\mathbf{9 9})$} & \multicolumn{2}{c}{$\mathbf{2 0 1 0}(\boldsymbol{n}=\mathbf{1 0 6})$} \\
\hline Quarterback & 22 & $22.2 \%$ & 20 & $18.9 \%$ \\
Offensive Lineman & 13 & $13.1 \%$ & 10 & $9.4 \%$ \\
Running Back/Receiver & 23 & $23.2 \%$ & 35 & $33.0 \%$ \\
Defensive Line/Linebacker & 26 & $26.3 \%$ & 23 & $21.7 \%$ \\
Defensive Back & 15 & $15.2 \%$ & 18 & $17.0 \%$ \\
\hline
\end{tabular}

Notes: Head Coaches: $\chi^{2}(4, n=205)=3.19, p>.05$ 
Table 5 Frequencies of Head Coaches by Position as a Player by Time

\begin{tabular}{lcccccc}
\hline Former Position Played & \multicolumn{2}{c}{$\mathbf{1 9 9 0}(n=\mathbf{6 9})$} & \multicolumn{2}{c}{$\mathbf{2 0 0 5}(\boldsymbol{n}=\mathbf{9 9})$} & \multicolumn{2}{c}{$\mathbf{2 0 1 0}(\boldsymbol{n}=\mathbf{1 1 5})$} \\
\hline Did Not Play & \multicolumn{2}{c}{ N/A } & 4 & $4.0 \%$ & 7 & $6.1 \%$ \\
Quarterback & 31 & $44.9 \%$ & 33 & $33.3 \%$ & 33 & $28.7 \%$ \\
Offensive Lineman & 15 & $21.7 \%$ & 12 & $12.1 \%$ & 13 & $11.3 \%$ \\
Running Back/Receiver & 6 & $8.7 \%$ & 16 & $16.2 \%$ & 18 & $15.7 \%$ \\
Defensive Line/Linebacker & 11 & $15.9 \%$ & 19 & $19.2 \%$ & 19 & $16.5 \%$ \\
Defensive Back & 6 & $8.7 \%$ & 15 & $15.2 \%$ & 25 & $21.7 \%$ \\
Special Teams & \multicolumn{2}{c}{ N/A } & \multicolumn{2}{c}{ N/A } & 0 & $0.0 \%$ \\
\hline
\end{tabular}

Notes: Head Coaches: $\chi^{2}(5, n=214)=2.29, p>.05$

Research Question 2 statistically addressed the potential impact a White or African American head coach might have on the racial make-up of his coaching staff. Significant differences were found, $\chi^{2}(2, n=1024)=7.52, p<.05$, such that White head coaches were more likely to have White assistant coaches than African American assistant coaches and vice versa. Nearly sixty-nine percent $(n=624)$ of White head coaches' staffs were made up of White assistant coaches, with $28.7 \%$ $(n=261)$ of their staffs being African American. African American head coaches had more diverse coaching staffs, with 58.6\% $(n=68)$ of their assistant coaches being White and 40.5\% $(n=47)$ being African American.

\section{Discussion}

The overall shift in the representation of African American coaches in DI-FBS college football reveals a positive and long awaited trend. Despite a slight decrease in representation at the offensive coordinator position (from 12 to 9), African American coaches showed significant increases in two of the three most prominent and influential positions in college football: head coach and defensive coordinator. The largest, and perhaps most inspiring change occurred at the head coaching position. Where only three programs (2.6\%) were under the guise of African Americans in 2005, 13 African American men now hold the highest of coaching positions in DI-FBS programs (11.2\%). Likewise, a significant increase was seen in the attainment of defensive coordinator positions, where African American representation rose from $8.1 \%$ to $17.2 \%$. Significant changes also occurred among assistant coaches, among whom there were 34 more African American and 7 fewer White coaches. These findings alone seem to suggest that African Americans are finding greater acceptance and achievements in the college football coaching field. Deeper analyses revealed even more changes in African American representation that suggest further promise for equality in the coaching ranks.

Finch et al. (2010) concluded the relegation of African American coaches into noncentral coaching positions (e.g., running backs and wide receivers) contributed to potential institutional racism, subsequently marginalizing the coaches' efforts, abilities, and opportunities. Thus, should this inclination have continued, African 
Americans would be overrepresented in the peripheral coaching positions (e.g., running backs and wide receivers). While this remains the case, the representation of African Americans as running back and wide receiver coaches has declined since 2005 , falling from $45.8 \%$ to $42.7 \%$. However, in the similarly noncentral coaching position of defensive backs and safeties, African American representation witnessed a steep rise from 2005 (18.7\%) to 2010 (24.8\%). Concurrently, African American coaches have seen a decline in their representation at the quarterback and offensive line coaching positions, $0.1 \%$ and $0.7 \%$ respectively. Keep in mind that as coaches find themselves in more peripheral positions, their skills and knowledge can be marginalized, their resources limited, and expectations often lowered (Anderson, 1993; Grusky, 1963; Sack et al., 2005). This can in turn hinder the coach's social and human capital (Sagas \& Cunningham, 2005), as well as his aspirations to persevere toward head coaching or other leadership roles (Cunningham, Bruening, \& Straub, 2006).

Thus, the aforementioned numbers would seemingly give credence to Finch et al.'s (2010) claim that African Americans continue to be "pushed out" into more peripheral (i.e., noncentral) coaching positions, and as a result, remain severely underrepresented in the most prestigious and visible of coaching roles. While such positions are a part of the aforementioned career coaching pipeline, Cunningham and Bopp (2010) found that African American assistant coaches were hired to instruct positions that have a high concentration of African American players. Perhaps this hiring pattern reveals token hires, and even token interviews (Lapchick, Benoit, \& Morris, 2010), of African American coaches that can better "relate to" and recruit African American players due to racial and/or ethnic similarities (Wong, 2002).

However, a trend favoring the decline in the overrepresentation of African Americans in peripheral positions is the coaching history of current head coaches. From 2005 to 2010, a shift in the coaching positions held by head coaches before obtaining their leadership role occurred. Historically, head coaches emerged from the White-dominated coaching positions of quarterback and offensive line. Despite African Americans' critical underrepresentation in the two coaching positions, half of all head coaches in 2010 previously coached the noncentral positions of running backs, wide receivers, and defensive backs. This trend bodes well for African Americans as they currently hold $54.4 \%$ of said coaching positions.

Similarly, a shift in more positive and accepting attitudes toward head coaches with diverse career backgrounds can be postulated by examining the former playing positions of head coaches. Recall that Anderson (1993) demonstrated a significant association between a player's race and the centrality of his position. More specifically, it was discovered that White assistant coaches were more than twice as likely to have played a central position (i.e., quarterback or offensive line); positions played by $66 \%$ of the head coaches in 1990 . This is a critical association to recognize as the current data reveals a positive trend toward parity in head coaches' playing experiences. A $4.6 \%$ decrease in head coaches playing quarterback and a $6.5 \%$ increase in head coaches having played defensive back (positions traditionally dominated by White and African Americans, respectively) was witnessed from 2005 to 2010 . Furthermore, only $40 \%$ of current head coaches played quarterback or along the offensive line, a 5.6\% decrease from 2005 and a $26.6 \%$ decrease from 1990. Conversely, $37.4 \%$ of current head coaches were former running backs, wide receivers, or defensive backs, an increase of $6 \%$ from 2005 
and a $20 \%$ increase since 1990 . These findings exemplify the continued positive shift of athletic departments opting for coaches with diverse playing careers, such as the predominantly African American occupied positions of running back/wide receiver $(15.7 \%)$ and defensive back $(21.7 \%)$.

This inference is supported in the playing experience of current assistant coaches. In this coaching career pipeline, it appears common practice that rookie coaches instruct the position they played. In the past, this practice may have helped to maintain the aforementioned caste system of college coaching. All the same, there has been an increase, 7.6\% in 2005-12.9\% in 2010, of African Americans playing the positions (i.e., quarterback and offensive line) from which head coach and coordinator positions were traditionally earned. This trend is helping to rectify a concern expressed by Finch et al. (2010). It was determined via the backgrounds of head coaches from 1990 to 2005 that the former playing and coaching experiences should have facilitated the advancement of African Americans into prestigious coaching positions, yet there were no significant increases in representation at the head coaches, or offensive or defensive coordinator positions. Such is not the case from 2005 to 2010. As already expressed, significant increases were found in the representation of African Americans among head coaches and defensive coordinators. Furthermore, $44 \%$ of 2010 head coaches and offensive/defensive coordinators were former quarterbacks $(22 \%)$ or defensive backs $(22 \%)$. Such positive shifts in the diversity of coaches' playing positions indicate that said playing positions may no longer be as relevant today in determining career rank and outcomes.

As previously discussed, 2010 was a record year for the representation of African American head coaches with 13 men running DI-FBS football programs. Cunningham and Sagas (2005) found support for potential access discrimination among basketball coaches, where African Americans were significantly underrepresented on White head coaches' coaching staffs. Cunningham (2010) adds that if access discrimination is indeed a contributor to the dearth of African American coaches, then the coaching staffs of Whites and African Americans will be racially divergent. Thus, another aim of this study was to determine if such discrimination might exist in college football.

It was found that on average, African Americans were represented at a ratio of 2:3 on African American head coaches' staffs while being represented at a ratio of only 3:7 on White head coaches' staffs. These findings add support to Cunningham and Sagas' (2005) claim that with regards to advantageous social networks, rather than following the adage "who you know", it might be better said "who you know who is racially similar" (p.157). Despite this sustaining practice of access discrimination, optimism was still provided. In fact, Day and McDonald (2010) found that social networks including high ranking and heterogeneous contacts proved more profitable for the social mobility of African American coaches than their White counterparts. However, as African American coaches have obtained more positions of leadership and influence, it has allowed for a "racial uplift" (Perkins, 1983) and a continued decrease in the racial divide among current coaches. Should the findings of Day and McDonald (2010) hold true and a racial uplift be taking place, this offers confidence for continuing racial equality among college football coaches.

As witnessed in this study, access appears to be an antecedent to coaching opportunities and intentions. Thus, future studies could delve more into the coaching position of coaches when they first enter into the field. The role of the graduate 
assistant could be viewed as the commencement of one's career coaching pipeline, and as such, would be an integral component when examining the potential existence of discrimination in coaching DI football. Currently, the representation of African Americans in graduate assistant roles is less than that of African American assistant coaches: $70.5 \%$ of graduate assistants at the DI level (FBS and Football Championship Subdivision) are white while 26.7\% are African American. The potential impact of this underrepresentation at an entry-level coaching position cannot be ignored.

Likewise, the impact of outside stakeholders (e.g., alumni and boosters) should not be disregarded, as the hiring of African American head coaches is not solely dependent upon playing/coaching history and social networks. At the college level of play, decisions can be heavily influenced by alumni and boosters, and some schools might fear that an African American head coach would potentially damage future contributions and support (Wong, 2002). As with potential token interviews, objectively measuring and analyzing the impact of alumni and boosters on the hiring process of head coaches is a seemingly arduous task (Lapchick, Jackson, \& Lilly, 2011) that falls outside the scope of this project yet is worthy of mention.

\section{Conclusion}

In 1993, Anderson suggested a career pipeline existed in college football that might have negatively impacted minority coaches, and in particular African Americans. He deemed this institutionalized discrimination to evolve from the peripheral positions coaches had played while in college; given that the primary playing positions from which head coaches emerged were those dominated by White athletes. Fifteen years later, Finch et al. (2010) argued that intentional treatment and access discrimination were greater factors in the underrepresentation of African American college football coaches. Yet, they found reason for optimism as more parity was discovered among the playing and coaching backgrounds of coaches, and in particular head coaches. Despite confidence in the numbers found here, sustained institutionalized practices and social networks continue to marginalize African American coaching efforts and opportunities, particularly at the head coach and coordinator positions. However, the underrepresentation of African American coaches appears to be dissipating and becoming more equitable. This positive trend toward a more equal racial representation of coaches was found to be continuing in the 2010 DI-FBS coaching field.

Increases in both the number and proportion of African American coaches took place among head coaches, defensive coordinators, and all assistant coaches. Greater parity was also found in the coaching and playing backgrounds of all coaching categories. Thus, the coaching career paths of current head coaches and coordinators appear to be paving a more equitable path for assistant and future coaches; thereby, potentially increasing (head) coaching intentions and more positive career opportunities of African Americans. While the trends noted in this study suggest positive change is occurring, the data continue to portray the existence of both institutional and access discrimination. These forms of biased hiring and promotion practices facilitate and maintain an underrepresentation of African American coaches in DI-FBS football; and while the increased acceptance of upper-level coaches with diverse racial, playing, and coaching backgrounds 
suggests a positive shift toward racial equality among coaches, the movement for a balanced representation perseveres.

\section{References}

Agyemang, K., \& DeLorme, J. (2010). Examining the dearth of Black head coaches at the NCAA Football Bowl Subdivision level: A critical race theory and social dominance theory analysis. Journal of Issues in Intercollegiate Athletics, 3, 35-52.

Anderson, D. (1993). Cultural diversity on campus: A look at intercollegiate football coaches. Journal of Sport and Social Issues, 17(1), 61-66.

Armstrong, K.L. (2011). 'Lifting the veils and illuminating the shadows': Furthering the explorations of race and ethnicity in sport management. Journal of Sport Management, 25, 95-106.

Buffington, D. (2005). Contesting race on Sundays: Making meaning out of the rise in the number of Black quarterbacks. Sociology of Sport Journal, 21, 19-37.

Burgess, D., \& Borgida, E. (1999). Who women are, who women should be: Descriptive and prescriptive gender stereotyping in sex discrimination. Psychology, Public Policy, and Law, 5, 665-692 10.1037/1076-8971.5.3.665.

Cunningham, G.B. (2010). Understanding the under-representation of African American coaches: A multilevel perspective. Sport Management Review, 13, 395-406 10.1016/j. smr.2009.07.006.

Cunningham, G.B., \& Bopp, T. (2010). Race ideology perpetuated: Media representations of newly hired football coaches. The Journal of Sports Medicine, 5, 1-20.

Cunningham, G.B., \& Sagas, M. (2005). Access discrimination in intercollegiate athletics. Journal of Sport and Social Issues, 29, 148-163.

Cunningham, G.B., Bruening, J.E., \& Straub, T. (2006). The under-representation of African Americans in NCAA Division I-A head coaching positions. Journal of Sport Management, 20, 387-413.

Day, J.C., \& McDonald, S. (2010). Not so fast my friend: Social capital and the race disparity in promotions among college football coaches. Sociological Spectrum, 30, 138-158 10.1080/02732170903495937.

Dufur, M., \& Feinberg, S.L. (2009). Race and the NFL draft: Views from the auction block. Qualitative Sociology, 32, 53-73 10.1007/s11133-008-9119-8.

Eagly, A.H., \& Karau, S.J. (2002). Role congruity theory of prejudice toward female leaders. Psychological Review, 109, 573-598.

Everhart, C.B., \& Chelladurai, P. (1998). Gender differences in preferences for coaching as an occupation: The role of self-efficacy, valence, and perceived barriers. Research Quarterly for Exercise and Sport, 69, 188-200 PubMed.

Finch, B., McDowell, J., \& Sagas, M. (2010). An examination of racial diversity in collegiate football: A 15 year update. Journal for the Study of Sports and Athletes in Education, 4, 47-57.

Grusky, O. (1963). The effects of formal structure on managerial recruitment: A study of baseball organization. Sociometry, 26, 345-353 10.2307/2786074.

Hawkins, B. (2002). Is stacking dead? A case study of the stacking hypothesis at a Southeastern Conference (SEC) football program. International Sports Journal, 6, 146-160.

Heilman, M.E. (2001). Description and prescription: How gender stereotypes prevent women's ascent up the organizational ladder. The Journal of Social Issues, 57, 657-674 $10.1111 / 0022-4537.00234$.

Kamphoff, C., \& Gill, D. (2008). Collegiate athletes' perceptions of the coaching profession. International Journal of Sports Science \& Coaching, 3, 55-72 10.1260/174795408784089351. 
Lapchick, R., Benoit, D., \& Morris, L. (2010). Protecting their turf: The Black Coaches and Administrators (BCA) hiring report card for NCAA FBS and FCS football head coaching positions (2009-10). Orlando, FL: The Institute for Diversity and Ethics in Sport, University of Central Florida.

Lapchick, R., Hoff, B., \& Kaiser, C. (2011). The 2010 racial and gender report card: College sport. Orlando, FL: The Institute for Diversity and Ethics in Sport, University of Central Florida.

Lapchick, R., Jackson, S., \& Lilly, A. (2011). Building positive change: The Black Coaches and Administrators (BCA) hiring report card for NCAA FBS and FCS football head coaching positions (2010-11). Orlando, FL: The Institute for Diversity and Ethics in Sport, University of Central Florida.

Lovett, D.J., \& Lowry, C.D. (1994). "Good old boys" and "good old girls" clubs: Myth or reality? Journal of Sport Management, 8, 27-35.

McCrudden, C. (1982). Institutional discrimination. Oxford Journal of Legal Studies, 2, 303-367. doi:10.1093/ojls/2.3.303

Perkins, L.M. (1983). The impact of the "cult of womanhood" on the education of black women. The Journal of Social Issues, 39(3), 17-28 10.1111/j.1540-4560.1983. tb00152.x.

Sack, A.L., Singh, P., \& Thiel, R. (2005). Occupational segregation on the playing field: The case of Major League Baseball. Journal of Sport Management, 19, 300-318.

Sagas, M., \& Cunningham, G.B. (2004). Treatment discrimination in college coaching: Its prevalence and impact on the career success of assistant basketball coaches. International Sports Journal, 8, 76-88.

Sagas, M., \& Cunningham, G.B. (2005). Racial differences in the career success of assistant football coaches: The role of discrimination, human capital, and social capital. Journal of Applied Social Psychology, 35, 773-797 10.1111/j.1559-1816.2005.tb02146.x.

Sagas, M., Cunningham, G.B., \& Pastore, D. (2006). Predicting head coaching intentions of male and female assistant coaches: An application of the theory of planned behavior. Sex Roles, 54, 695-705.

Sartore, M.L., \& Cunningham, G.B. (2006). Stereotypes, race, and coaching. Journal of African American Studies (Lawrence, Kan.), 10, 69-83.

Telles, E.E., \& Lim, N. (1998). Does it matter who answers the race question? Racial classification and income inequality in Brazil. Demography, 35, 465-474. PubMed doi: $10.2307 / 3004014$

Wong, E. (2002). The mystery of the missing minority coaches. New York Times Online.

Retrieved July 20, 2011 from http://www.nytimes.com/2002/01/06/weekinreview/ideastrends-getting-with-program-mystery-missing-minority-coaches.html

Woodward, J.R. (2004). Professional football scouts: An investigation of racial stacking. Sociology of Sport Journal, 21, 356-375.

Zgonc, E. (2010a). Race and gender demographics: 2008-09 NCAA member institutions' personnel report. Indianapolis, IN: The National Collegiate Athletic Association.

Zgonc, E. (2010b). Student-athlete ethnicity: 1999-2000 - 2008-10 NCAA student-athlete ethnicity report. Indianapolis, IN: The National Collegiate Athletic Association. 